\title{
Evolution of PBL from normal epithelium to DCIS
}

\author{
S. K. Mohsin, D. C. Allred \\ The Breast Center and Department of Pathology, Baylor College of Medicine, Houston, TX, USA.
}

\begin{abstract}
A$ large number of studies in the last three decades have identified only a handful of biological features in the evolution of human premalignant breast lesions (PBL). They have shown that PBL have a positive growth balance, which may be driven/regulated by oestrogen receptor, erbB-2, and p53. There is marked genetic diversity in PBL, and use of newer technologies such as SAGE, DNA microarrays, and high-throughput proteomics will significantly improve our understanding of evolution of PBL over the next decade.
\end{abstract}

Keywords: Breast cancer; Premalignant; Hyperplasia; Atypical ductal hyperplasia; Ductal carcinoma in situ

\section{Introduction}

It is believed that all invasive breast cancers (IBC) develop over long periods of time from certain benign proliferative lesions, however; only a few of these have been well established as premalignant breast lesions (PBL). By definition, PBL show a variable loss of growth control, but they lack the ability to invade or metastasize. This delay in time to progress provides a rationale for preventive intervention and use of tamoxifen, which targets oestrogen receptor (ER), has been successful. However, not all ER-positive IBCs are prevented by this therapy and it has become imperative to identify new targets for prevention by developing better understanding of biological and genetic evolution of PBL.

There are at least four converging lines of evidence that have defined the most important precursors of IBC, that is atypical ductal hyperplasia (ADH), atypical lobular hyperplasia, ductal carcinoma in situ (DCIS), and lobular carcinoma in situ and to certain extent early lesions like usual ductal hyperplasia (UDH) and hyperplastic unfolded lobules (HULs; also known as blunt duct adenosis and columnar cell lesions).

Correspondence to: Syed K. Mohsin MD, Associate Professor of Pathology, The Breast Center, Baylor College of Medicine, One Baylor Plaza - BCM-600, Houston, TX 77030, USA. E-mail: smohsin@breastcenter. tmc.edu; Tel: +1713 798 1628; Fax: +1713798 1659

Publication date 16/11/04

BCO/46/2002/FO
The supporting evidence comes from the fact that pathologists have recognized many years ago that these PBL were on a histological continuum and were much more common in breasts with synchronous IBC than noncancerous breasts [1]; long-term followup studies have shown that women with these PBL are at increased risk for developing IBC [2]; they share identical genetic abnormalities with synchronous IBC [3]; and xenografts and genetically engineered animal models show analogous histological evolution [4]. All of this evidence has culminated in a model of breast cancer evolution proposing that stem cells in normal terminal duct lobular units (TDLUs) give rise to hyperplasias, which give rise to atypical hyperplasias, which progress to in situ carcinomas, which eventually progress to invasive and metastatic disease.

The evolution of IBC has been difficult to study because these human PBLs are microscopic in size, with the exception of DCIS, and available mostly as formalin-fixed paraffin-embedded tissue. Although there have been hundreds of studies during the past three decades evaluating a large number of biological pathways in PBL, but most were limited to conventional technologies such as immunohistochemistry $(\mathrm{IHC})$, and only recently have used high-throughput technologies such as SAGE and DNA microarrays. Nonetheless, these studies emphasized that there are underlying biological abnormalities causing some PBL to remain stable and others to progress. 
This review will focus on features of the few wellestablished PBL using traditional techniques and briefly mention a few of the more interesting but unconfirmed findings from newer studies.

\section{Biological features of premalignant lesions}

Several biological abnormalities used routinely to help determine the prognosis and treatment of patients with IBC were subsequently studied in its putative precursors including assessments of growth balance, hormone receptors, oncogenes, and tumour suppressor genes.

\section{Growth balance (proliferation and apoptosis)}

Many studies, using a variety of techniques, have measured the magnitude of proliferation in TDLUs and PBL (Table 1). In TDLUs, proliferation averages about $2 \%$ and in premenopausal women, the rate fluctuates with the menstrual cycle. In HULs one preliminary study reported an average rate of about $5 \%$, which is similar to the observed rates in $\mathrm{ADH}$ [5]. There is substantial data that proliferation is proportional to differentiation along the histological continuum in DCIS with rates averaging as low as $1 \%$ in the low-grade to more than $70 \%$ in the highgrade lesions [6]. The average proliferation rate in all DCIS combined is about $15 \%$.

The data on apoptosis, the other side of the growth equation is very limited (Table 1). There is preliminary report that the apoptosis rate is about $0.6 \%$ in TDLUs and $0.3 \%$ in ADH [7]. In DCIS, apoptosis seems to vary with histological differentiation in

Table 1. Summary of biological features of PBL assessed by IHC.

\begin{tabular}{llllll}
\hline & TDLU & HUL & UDH & ADH & DCIS \\
\hline $\begin{array}{l}\text { Proliferation rate } \\
\text { Average \% } \\
\text { positive cells }\end{array}$ & 2 & 5 & 5 & 5 & 15 \\
$\begin{array}{l}\text { Apoptosis rate } \\
\begin{array}{l}\text { Average \% } \\
\text { positive cells }\end{array}\end{array}$ & 0.6 & $?$ & $?$ & 0.3 & 2.5 \\
$\begin{array}{l}\text { ER } \\
\% \text { lesions with }\end{array}$ & 95 & 95 & 95 & 95 & 95 \\
$\begin{array}{l}\text { ER-positive cells } \\
\text { cells in a lesion }\end{array}$ & 30 & 90 & 60 & 90 & 45 \\
$\begin{array}{l}\text { erbB-2 overexpression/amplification } \\
\% \text { abnormal lesions }\end{array}$ & 0 & 0 & 0 & 1 & 30 \\
$\begin{array}{l}\text { p53 overexpression/mutation } \\
\% \text { abnormal lesions }\end{array}$ & 0 & 0 & 0 & 0 & 30 \\
\hline $\begin{array}{l}\text { ? no data in literature for these categories } \\
\text { n }\end{array}$ & & & &
\end{tabular}

DCIS, being much lower in low-grade (1\%) than highgrade lesions (5\%) [8]. Hence, it appears that the growth of PBLs is likely due to both increased proliferation and decreased cell death and this equilibrium is probably controlled by a variety of regulatory mechanisms, such as sex hormones, oncogenes, tumour suppressor genes, and many other as yet unknown genetic and epigenetic abnormalities.

\section{Oestrogen receptor}

Oestrogen, via the ER, plays a central role in regulating the growth and differentiation of normal breast epithelium. For women of all ages combined, an average of about $30 \%$ of cells in normal TDLUs express ER $\alpha$ (Table 1) and in premenopausal women, the rate is somewhat lower, about $20 \%$, and varies with the menstrual cycle [9]. The average proportion of ER $\alpha$-positive cells in TDLUs in postmenopausal women is about $50-60 \%$. In HULs, preliminary data suggests that a large majority express the receptor in over $90 \%$ of cells. In $\mathrm{ADH}>90 \%$ of lesions express very high levels of $\mathrm{ER} \alpha$ in nearly all cells. In DCIS, overall $75 \%$ of all cases express $\mathrm{ER} \alpha$ and its expression varies with histological differentiation in DCIS, being highest in low-grade lesions (90-100\%), and lowest in high-grade lesions (0-30\%) [10].

The very high levels of ER $\alpha$ observed in nearly all premalignant lesions may contribute to their increased proliferation relative to normal cells by allowing them to respond more effectively to any level of oestrogen, even the low concentrations observed in postmenopausal women. Besides $\mathrm{ER} \alpha$, very little is known about the involvement of other types of hormone receptors in PBL. The results of one recent preliminary report suggest that the level of $E R \beta$ is significantly lower in most premalignant lesions compared to normal epithelium, which is opposite to that of $\mathrm{ER} \alpha$, despite the high degree of structural homology between the two receptors [11].

\section{Oncogenes and tumour suppressor genes}

erbB-2 plays important role in cell growth, differentiation, adhesion, and motility that could contribute to the ability of tumour cells overexpressing erbB-2 to invade and metastasize. Overexpression and amplification of erbB-2 has not been observed in TDLUs or UDH (Table 1). It has been detected only rarely in $\mathrm{ADH}$, although a recent study found amplification of the gene (up to sixfold), in the apparent absence of protein overexpression, in $50 \%$ of $\mathrm{ADH}$ from breasts containing IBC [12]. In DCIS, many studies have shown that erbB-2 overexpression is rare in lowgrade DCIS but seen in $30-40 \%$ of high-grade DCIS [13]. Just how alterations of erbB-2 lead to the 
development and progression of premalignant breast disease is not entirely clear.

Alterations of p53 also appear to play an important role in the evolution of PBL. With the exception of morphologically 'normal' breast epithelium in Li-Fraumeni patients with inherited mutations, abnormalities of p53 have not been reported in TDLUs. There are no formal studies of p53 in HULs. A single study looking at p53 in UDH found slightly elevated levels of protein in a small subset of lesions. p53 also appears to be normal in nearly all $\mathrm{ADH}$. p53 in DCIS is quite rare (about 5\%) in lowgrade lesions, and relatively common (about 40\%) in high-grade lesions (Table 1). Mutations of p53 may contribute to the development and progression of premalignant breast disease by several mechanisms including interference with DNA repair through loss of an important G1 cell-cycle checkpoint, leading to replication of a damaged DNA template and genetic instability, and also perhaps by clonal expansion through inhibition of programmed cell death.

\section{Prognostic significance of biological markers in PBL}

Only a few studies have evaluated the prognostic value of these markers and have either failed to show any significance or early promising results have not been reproducible.

\section{Genetic features of premalignant lesions}

\section{Allelic imbalances}

Most of the genetic abnormalities responsible for the development and progression of PBL are still unknown. Studies of loss of heterozygosity $(\mathrm{LOH})$ analysis or comparative genomic hybridization $(\mathrm{CGH})$ and many other methodologies over the past decade provide crude but compelling evidence that IBC evolves from premalignant lesions by highly diverse genetic and epigenetic mechanisms. These studies have assessed allelic imbalance (AI) to identify the general chromosomal locations of tumour suppressor genes (through losses) or amplified oncogenes (through gains) that may be important in the evolution of PBL (Table 2).

An interesting study noted that histologically normal TDLUs shared LOH with closely adjacent IBC, while TDLUs farther away in the same breast did not, demonstrating that even normal appearing epithelium may have genotypic abnormalities associated with an elevated risk for developing breast cancer [14]. There is only one preliminary study in a subset of HULs that identified losses at 9q, 17p, and 17q [15]. A few studies in UDH found about 30\% Als involving at least 10 loci on 8 chromosomes. Studies in $\mathrm{ADH}$ have shown that up to $50 \%$ contain one or more Als at 30 genetic loci distributed over 10 chromosomes. Studies have shown that nearly all DCIS contain at least one $\mathrm{Al}$ among more than 100 genetic loci on 17 chromosomes. Not surprisingly, Als are more common and numerous in DCIS, especially high-grade lesions than in hyperplasias, consistent with the notion that they represent a relatively late stage of evolution [10].

To identify genetic changes that may be important in progression to IBC, several studies have compared genetic profile between pure DCIS and DCIS with synchronous IBC. Following this strategy, the loci that seem to be important favouring progression include 2q (10-40\%), 11p (20-70\%), 13q (10-40\%), and $17 q(5-40 \%)$, and those that may protect against progression include $13 q$ and $17 q$.

\section{Preliminary data from gene expression profiling technology}

Many of the innovative high-throughput technologies such as gene expression profiling require fresh/ frozen tissue, so the fact that fixed-archival tissue is still the primary resource available for normal and most PBLs remains a problem, but a few recent studies relying on small collections of frozen samples have demonstrated the enormous potential of these new tools to advance our understanding of premalignant evolution.

One of the studies used SAGE to compare the expression of 16000 gene transcripts in normal epithelium, DCIS, and IBC and found dramatic differences in expression profiles between normal and DCIS but noted that profiles in DCIS and IBC are highly similar [16]. For example, only 16 genes were expressed at significantly different levels in DCIS compared to IBC, 5 being relatively upregulated in DCIS and 11 relatively upregulated in IBC.

Table 2. Summary of $\mathrm{Al}$ (gains and losses) in PBL from studies assessing $\mathrm{LOH}$ and $\mathrm{CGH}$.

\begin{tabular}{lll}
\hline Category & Gains & Losses \\
\hline TDLU & Unknown & Unknown \\
HUL & Unknown & 9q, 17p, 17q \\
UDH & $1 q$ & $\begin{array}{l}1 p, 8 p, 11 q, 16 q, 17 p, \\
\text { 17q, 20p, 21q, 22q }\end{array}$ \\
ADH & $1 q, 8 q, 10 q$, & $1 q, 2 p, 3 q, 6 q, 8 p, 9 p, 11 p, 11 q, 13 q$, \\
& $11 q, 14 q, 16 p$ & $14 q, 16 q, 17 p, 17 q, 20 p, 21 q$, Xq \\
DCIS & $1 q, 3 q, 6 p$, & $1 p, 1 q, 2 p, 2 q, 3 p, 3 q, 4 p, 6 p$, \\
& $6 q, 8 q, 17 q$, & $6 q, 7 p, 7 q, 8 p, 8 q, 9 p, 11 p$, \\
& $20 q$, Xq & $11 q, 12 p, 13 q, 14 q, 15 q, 16 p, 16 q$, \\
& & $17 p, 17 q, 18 q, 21 q$
\end{tabular}


Table 3. List of putative genes (relatively up- or downregulated in DCIS as compared to IBC) identified by high-throughput expression array studies that are differentially expressed and thus may be involved in the progression of DCIS to IBC.

\begin{tabular}{ll}
\hline Upregulated & Downregulated \\
\hline S-100A7/psoriasin & COLL11A \\
TFF3 & SECTM1 \\
S-100A9 & KIFC1 \\
APOD & \\
AAMP & \\
TGF-1 & \\
PTN & \\
TGF $\beta$ R3 & \\
CCASAMG & \\
ITGA2 & \\
BRAG-1 & \\
COLL17A1 & \\
SERPINA1 & \\
MYH11 & \\
ACTG2 & \\
KRT5 & \\
PIP &
\end{tabular}

Among these genes, upregulation of $\mathrm{S}-100 \mathrm{~A} 7 /$ psorisin in high-grade DCIS has been confirmed using reverse transcriptase-polymerase chain reaction (RT-PCR) also.

A few recent preliminary studies have used DNA microarrays to study gene expression in the evolution of PBLs. One such study compared nearly 6000 transcripts between 10 cases of low and high-grade DCIS, and identified 69 genes that were expressed at significantly different levels between the two groups [17]. Another study compared 12000 transcripts in a larger cohort of samples including ADH, DCIS, and IBC and found gene expression profiles were found to be highly similar in DCIS and IBC, but a signature of 85 genes separated DCIS and IBC [18]. The overall patterns of gene expression were more different between histological grades of the same type of lesions (e.g. low-grade vs. high-grade DCIS) than they were between different stages of lesions (e.g. DCIS vs. IBC), although 85 genes involved in many different biological pathways were expressed at significantly different levels in DCIS compared to IBC. A similar study studied 12000 transcripts, comparing DCIS and IBC and found more than 200 differentially expressed genes between the two groups. Twentysix genes of the genes showed from four- to tenfold differences between DCIS and IBC (Table 3) [19].

\section{Acknowledgements}

This work was supported by NIH grant P50 CA 58183 (Specialized Program of Research Excellence in Breast Cancer).

\section{References}

1. Wellings SR, Jensen HM, Marcum RG. An atlas of subgross pathology of the human breast with special reference to possible precancerous lesions. I Natl Cancer Inst 1975; 55: 231-243.

2. Dupont WD, Page DL. Risk factors for breast cancer in women with proliferative breast disease. New Engl $J$ Med 1985; 312: 146-151.

3. O'Connell P, Pekkel V, Fuqua SAW, Osborne CK, Allred DC. Analysis of loss of heterozygosity in 399 premalignant breast lesions at 15 genetic loci. $J$ Natl Cancer Inst 1998; 90: 697-703.

4. Medina D. The preneoplasitc phenotype in murine mammary tumorigenesis. J Mammary Gland Biol and Neoplasia 2000; 5(4): 393-407.

5. Mohsin SK, Hilsenbeck SG, Allred DC. Estrogen receptors and growth control in premalignant breast disease. Modern Pathol 2000; 13(28A): 145.

6. Berardo M, Hilsenbeck SG, Allred DC. Histological grading of noninvasive breast cancer and its relationship to biological features. Lab Invest 1996; 74(15A): 68.

7. Prosser J, Hilsenbeck SG, Fuqua SAW, O'Connell P, Osborne CK, Allred DC. Cell turnover (proliferation and apoptosis) in normal epithelium and premalignant lesions in the same breast. Lab Invest 1997; 76: 119 [Abstract 24A].

8. Bodis S, Siziopikou KP, Schnitt SJ, Harris JR, Fisher DE. Extensive apoptosis in ductal carcinoma in situ of the breast. Cancer 1996; 77: 1831-1835.

9. Allegra JC, Lippman ME, Green L, Barlock A, Simon R, Thompson EB, et al. Estrogen receptor values in patients with benign breast disease. Cancer 1979; 44: 228-231.

10. Allred DC, Hilsenbeck SG, Mohsin SK. Biologic features of human premalignant breast disease. In: Harris JR, Lippman ME, Morrow M, Osborne CK (Eds). Diseases of the Breast, 3rd edition. Hagerstown, MD: Lippincott Williams \& Wilkins; 2004: 507-520.

11. Roger P, Sahla ME, Makela S, Gustafsson JA, Baldet P, Rochefort H. Decreased expression of estrogen receptor beta protein in proliferative preinvasive mammary tumors. Cancer Res 2001; 61(6): 2537-2541.

12. $\mathrm{Xu} R$, Perle MA, Inghirami G, Chan W, Delgado $Y$, Feiner H. Amplification of Her-2/neu gene in Her-2/neuoverexpressing and nonexpressing breast carcinomas and their synchronous benign, premalignant, and metastatic lesions detected by FISH in archival material. Mod Pathol 2002; 15(2): 116-124.

13. Allred DC, Clark GM, Molina R, Tandon AK, Schnitt SJ, Gilchrist KW, et al. Overexpression of HER-2/neu and its relationship with other prognostic factors change during the progression of in situ to invasive breast cancer. Hum Pathol 1992; 23: 974-979.

14. Deng G, Lu Y, Zlotnikov G, Thor AD, Smith HS. Loss of heterozygosity in normal tissue adjacent to breast carcinomas. Science 1996; 274: 2057-2059.

15. Dabbs DJ, Fudge M, Peng Y, Carter G, Swalsley P, Finkelstein $S$. Molecular alterations in columnar cell lesions of the breast. Mod Pathol 2004; 17(Suppl 1): 27A [Abstract 100].

16. Porter D, Lahti-Domenici J, Keshaviah A, Bae YK, Argani $\mathrm{P}$, Marks $\mathrm{J}$, et al. Molecular markers in ductal carcinoma in situ of the breast. Mol Cancer Res 2003; 1(5): 362-375. 
17. Adeyinka A, Emberley E, Niu Y, Snell L, Murphy LC, Sowter $\mathrm{H}$, et al. Analysis of gene expression in ductal carcinoma in situ of the breast. Clin Cancer Res 2002; 8(12): 3788-3795.

18. Ma XJ, Salunga R, Tuggle JT, Gaudet J, Enright E, McQuary P, et al. Gene expression profiles of human breast cancer progression. Proc Natl Acad Sci USA 2003; 24: 24.

19. Allred DC, Wu Y, Tsimelzon A, Hilsenbeck SG, Osborne CK, O'Connell P. The progression of DCIS to IBC: a cDNA expression microarray study. Breast Cancer Res Treat 2002; 76(S1): S81 [Abstract 288]. 